\title{
Tamanho de parcela e número de repetições em feijão de porco
}

\author{
Plot size and number of replicates in jack bean
}

\begin{abstract}
Alberto Cargnelutti Filho' ${ }^{\text {I }}$ Marcos Toebe ${ }^{\text {II }}$ Cláudia Burin II Bruna Mendonça Alves ${ }^{\text {II }}$ Ismael Mario Márcio Neu ${ }^{\text {III }}$ Gabriele Casarotto ${ }^{\text {IV }}$ Giovani Facco $^{\text {II }}$
\end{abstract}

RESUMO

Os objetivos deste trabalho foram determinar $o$ tamanho ótimo de parcela e o número de repetições para avaliar caracteres de feijão de porco (Canavalia ensiformis). Foram realizados seis ensaios de uniformidade de $5 \mathrm{~m} \times 5 \mathrm{~m}\left(25 \mathrm{~m}^{2}\right)$. Cada ensaio foi dividido em 25 unidades experimentais básicas (UEB) de $1 \mathrm{~m} \times 1 \mathrm{~m}$, totalizando 150 UEB. Foi pesada a massa verde de vagens $(M V V)$ e a massa verde de parte aérea sem vagens (MVPASV) $e$ calculada a massa verde de parte aérea $(M V P A=M V V+M V P A S V)$ das plantas de cada UEB. Foi determinado o tamanho ótimo de parcela e comparadas as médias entre os caracteres $M V V, M V P A S V$ e MVPA. Após, foi calculado o número de repetições. Os tamanhos ótimos de parcela para avaliar a massa verde de vagens, a massa verde de parte aérea sem vagens e a massa verde de parte aérea são, respectivamente, $8,59 \mathrm{~m}^{2}, 6,14 \mathrm{~m}^{2}$ e 5,85 $\mathrm{m}^{2}$. Quatro repetições, para avaliar até 50 tratamentos, no delineamento blocos ao acaso, são suficientes para identificar, como significativas a 5\% de probabilidade, pelo teste de Tukey, diferenças entre médias de tratamentos de 55,48\%, 39,66\% e 37,78\% das médias de massa verde de vagens, de massa verde de parte aérea sem vagens e de massa verde de parte aérea do experimento, respectivamente.

Palavras-chave: Canavalia ensiformis, planejamento experimental, precisão experimental.

\section{ABSTRACT}

The objectives of this research were to determine the optimum plot size and the number of repetitions to evaluate characters of jack bean (Canavalia ensiformis). It was carried six uniformity assays of size $5 m \times 5 m\left(25 m^{2}\right)$. Each assay was divided in 25 basic experimental units (UEB) of $1 \mathrm{~m} \times 1 \mathrm{~m}$, totaling $150 U E B$. The fresh mass of pods (MVV) and fresh mass of aerial part without pods (MVPASV) were weighed and fresh mass of the aerial part $(M V P A=M V V+M V P A S V)$ of plants of each $U E B$ was calculated. The optimum plot size was determined and the means were compared, between characters MVV, MVPASV and MVPA. The number of replicates was determined. The optimum plot sizes to evaluate the fresh mass of pods, fresh mass of aerial part without pods and fresh mass of aerial part are, respectively, $8.59 \mathrm{~m}^{2}, 6.14 \mathrm{~m}^{2}$ and $5.85 \mathrm{~m}^{2}$. Four replications, to evaluate up to 50 treatments, in randomized block designs, are sufficient to identify, as significant at the 5\% probability by Tukey test, differences between treatment means $55.48 \%, 39.66 \%$ and $37.78 \%$ of the average fresh mass of pods, fresh mass of aerial part without pods and fresh mass of aerial part of the experiment, respectively.

Key words: Canavalia ensiformis, experimental design, experimental precision.

\section{INTRODUÇÃO}

O feijão de porco (Canavalia ensiformis) é uma espécie leguminosa utilizada para adubação verde e cobertura de solo (LOPES, 1998). Pesquisas com o feijão de porco e outras espécies, envolvendo aspectos relacionados à produção de massas verde e/ ou seca (CARNEIRO et al., 2008; TEIXEIRA et al., 2008; ALMEIDA \& CAMARA, 2011; CESAR et al., 2011; CARDOSO et al., 2013; CARVALHO et al., 2013; MAIA et al., 2013), índice de cobertura do solo (CARDOSO et al., 2013; CARVALHO et al., 2013), teor, acúmulo e liberação de nutrientes (TEIXEIRA et al., 2008; TEIXEIRA et al., 2010; ALMEIDA \& CAMARA, 2011; CESAR et al., 2011) e alterações

\footnotetext{
'Departamento de Fitotecnia, Centro de Ciências Rurais (CCR), Universidade Federal de Santa Maria (UFSM), 97105-900, Santa Maria, RS, Brasil. E-mail: alberto.cargnelutti.filho@gmail.com. Autor para correspondência.

IPrograma de Pós-graduação em Agronomia, UFSM, Santa Maria, RS, Brasil.

IIICurso de Agronomia, UFSM, Santa Maria, RS, Brasil.

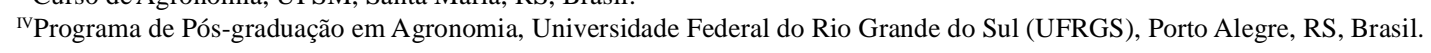
Recebido 28.02.14 Aprovado 08.05.14 Devolvido pelo autor 02.07.14 CR-2014-0317
} 
na atividade e biomassa microbiana de solo (CARNEIRO et al., 2008) têm sido desenvolvidas. De maneira geral, essas pesquisas apontaram características promissoras do feijão de porco.

Em experimentos com plantas de cobertura, é importante dimensionar o tamanho ótimo de parcela e o número de repetições a ser utilizado, a fim de obter resultados precisos. Para avaliar a produção de fitomassa de feijão de porco e de outras oito espécies de cobertura do solo e verificar as alterações na atividade e biomassa microbiana de solo de cerrado, CARNEIRO et al. (2008) utilizaram parcelas de $25 \mathrm{~m}^{2}$ $(5 \mathrm{~m} \times 5 \mathrm{~m})$. A fim de avaliar a produção de biomassa e o teor de macronutrientes do milheto, do feijão de porco e do guandu anão, em cultivo solteiro e consorciado, TEIXEIRA et al. (2008) usaram parcelas de $50 \mathrm{~m}^{2}(10 \mathrm{~m} \times 5 \mathrm{~m})$ e área útil de $6 \mathrm{~m}^{2}$. A liberação de macronutrientes das palhadas de milheto solteiro e consorciado com feijão de porco sob cultivo de feijão foi estudada por TEIXEIRA et al. (2010), em parcelas de $12,5 \mathrm{~m}^{2}(2,5 \mathrm{~m} \times 5 \mathrm{~m})$. Pretendendo estudar a quantidade de massa seca e o acúmulo de nutrientes em feijão de porco e outras espécies, ALMEIDA \& CAMARA (2011) utilizaram parcelas de $12 \mathrm{~m}^{2}$ $(6 m \times 2 m)$. Em estudo desenvolvido por CESAR et al. (2011), para avaliar a performance de feijão de porco e de outras dez espécies de leguminosas como adubos verdes, os autores utilizaram parcelas de $40 \mathrm{~m}^{2}$ $(4 \mathrm{~m} \times 10 \mathrm{~m})$, com área útil de $30 \mathrm{~m}^{2}$ e a massa verde foi avaliada em $5 \mathrm{~m}^{2}$. A fim de avaliar o índice de cobertura do solo, as produtividades de massa verde e matéria seca, no cultivo de Crotalária júncea, feijão de porco e milheto, CARDOSO et al. (2013) utilizaram parcelas de $48 \mathrm{~m}^{2}(4 \mathrm{~m} \times 12 \mathrm{~m})$, sendo as avaliações de massa verde realizadas nas parcelas em três pontos de $1 \mathrm{~m}^{2}$. Na avaliação do desempenho agronômico de feijão de porco e de outras cinco espécies de cobertura, CARVALHO et al. (2013) utilizaram parcelas de $16 \mathrm{~m}^{2}(4 \mathrm{~m} \times 4 \mathrm{~m})$, com área útil de $9 \mathrm{~m}^{2}$. O efeito de densidades de semeadura, na produção de biomassa de feijão de porco, foi estudado por MAIA et al. (2013), com parcelas de $2 \mathrm{~m}^{2}$. Nesses estudos, foram utilizadas três repetições (CARDOSO et al., 2013), quatro repetições (TEIXEIRA et al., 2008, TEIXEIRA et al., 2010, ALMEIDA \& CAMARA, 2011, CESAR et al., 2011, MAIA et al., 2013) e cinco repetições (CARNEIRO et al., 2008) no delineamento blocos ao acaso.

Com base em dados obtidos em experimentos em branco, denominados ensaios de uniformidade (experimento sem tratamento), é possível determinar o tamanho ótimo de parcela e o número de repetições. O método da curvatura máxima do modelo do coeficiente de variação (PARANAÍBA et al., 2009) foi utilizado por CARGNELUTTI FILHO et al. (2011), no dimensionamento do tamanho ótimo de parcela para a mensuração da massa verde de nabo forrageiro. No entanto, em outras plantas de cobertura de solo, como o feijão de porco, investigações sobre o tamanho ótimo de parcela e o número de repetições, para avaliar a massa verde de vagens, a massa verde de parte aérea sem vagens e a massa verde de parte aérea, não foram encontradas na literatura. Assim, os objetivos deste trabalho foram determinar o tamanho ótimo de parcela e o número de repetições para avaliar caracteres de feijão de porco (Canavalia ensiformis).

\section{MATERIAL E MÉTODOS}

Foram conduzidos seis ensaios de uniformidade (experimentos em branco) com a cultura de feijão de porco (Canavalia ensiformis) numa área experimental de $16 \mathrm{~m} \times 16 \mathrm{~m}\left(256 \mathrm{~m}^{2}\right)$, do Departamento de Fitotecnia, da Universidade Federal de Santa Maria, Santa Maria, Estado do Rio Grande do Sul, a $29^{\circ} 42^{\prime}$ S, $53^{\circ} 49^{\prime} \mathrm{W}$ e a $95 \mathrm{~m}$ de altitude. A semeadura de feijão de porco foi realizada no dia 12 de novembro de 2010 e o espaçamento foi de $0,5 \mathrm{~m}$ entre fileiras e $0,125 \mathrm{~m}$ na fileira, totalizando 16 sementes $\mathrm{m}^{-2}$. A adubação de base foi de $40 \mathrm{~kg} \mathrm{ha}^{-1} \mathrm{de}$ $\mathrm{N}, 150 \mathrm{~kg} \mathrm{ha}^{-1}$ de $\mathrm{P}_{2} \mathrm{O}_{5}$ e $100 \mathrm{~kg} \mathrm{ha}^{-1}$ de $\mathrm{K}_{2} \mathrm{O}$ e os tratos culturais foram realizados de forma homogênea, em toda a área experimental.

Cada ensaio de uniformidade de tamanho $5 \mathrm{~m} \times 5 \mathrm{~m} \quad\left(25 \mathrm{~m}^{2}\right)$ foi dividido em 25 unidades experimentais básicas (UEB) de $1 \mathrm{~m} \times 1 \mathrm{~m}\left(1 \mathrm{~m}^{2}\right)$, formando uma matriz de cinco linhas e cinco colunas. Aos 199 dias após a semeadura, em cada UEB de $1 \mathrm{~m}^{2}$, foram cortadas as plantas, junto à superfície do solo. Após foram pesadas a massa verde de vagens (MVV, em gramas $\mathrm{m}^{-2}$ ) e a massa verde de parte aérea sem vagens (MVPASV, em gramas $\mathrm{m}^{-2}$ ). Depois foi calculada a massa verde de parte aérea $\left(\mathrm{MVPA}=\mathrm{MVV}+\mathrm{MVPASV}\right.$, em gramas $\mathrm{m}^{-2}$ ).

Com base nos dados das 25UEB, em cada ensaio de uniformidade e para cada caractere (MVV, MVPASV e MVPA), foram determinados o coeficiente de autocorrelação espacial de primeira ordem $(\rho)$, a variância $\left(\mathrm{s}^{2}\right)$, a média $(\mathrm{m})$ e o coeficiente de variação do ensaio (CV), em percentagem. A estimativa de $\rho$ foi obtida no sentido das linhas, conforme metodologia de PARANAÍBA et al. (2009). Para isso, iniciou-se o caminhamento a partir da UEB localizada na linha 1 , coluna 1 , até a linha 1 , coluna 5 , retornando a partir da linha 2, coluna 5, até a linha 2, coluna 1, e, assim, sucessivamente, até completar o caminhamento na 
UEB localizada na linha 5, coluna 5. Em cada ensaio, foram determinados o tamanho ótimo de parcela (Xo) pelo método da curvatura máxima do modelo do coeficiente de variação e o coeficiente de variação no tamanho ótimo de parcela $\left(\mathrm{CV}_{\mathrm{Xo}}\right)$, em percentagem,

por meio de $\quad X o=\frac{10 \sqrt[3]{2\left(1-\rho^{2}\right) s^{2} m}}{m} \quad$ e $\mathrm{CV}_{\mathrm{Xo}}=\frac{\sqrt{\left(1-\rho^{2}\right) \mathrm{s}^{2} / \mathrm{m}^{2}}}{\sqrt{\mathrm{Xo}}} \times 100$, respectivamente (PARANAÍBA et al., 2009). Assim, para cada caractere, foram obtidas seis estimativas das estatísticas $\rho, s^{2}, m, C V$, Xo e $\mathrm{CV}_{\mathrm{Xo}}$.

A seguir, para as seis estimativas de cada estatística $\left(\rho, s^{2}, \mathrm{~m}, \mathrm{CV}\right.$, Xo e $\mathrm{CV}_{\mathrm{Xo}}$ ), foram anotados os valores mínimo e máximo e calculadas a média, o desvio padrão, o coeficiente de variação e o valor-p do teste de normalidade de Kolmogorov-Smirnov. A comparação das médias das estatísticas $\rho, \mathrm{s}^{2}, \mathrm{~m}$, $\mathrm{CV}$, Xo e $\mathrm{CV}_{\mathrm{Xo}}$ entre os caracteres ( $\mathrm{n}=6$ ensaios de uniformidade) foi realizada por meio do teste $\mathrm{t}$ de Student (unilateral) para amostras dependentes, a $5 \%$ de probabilidade. Essas comparações de médias foram feitas duas a duas, ou seja, MVV versus MVPASV, MVV versus MVPA e MVPASV versus MVPA.

A diferença mínima significativa (d) do teste de Tukey, expressa em percentagem da média do experimento, é estimada pela expressão

$\mathrm{d}=\frac{\mathrm{q}_{\alpha(\mathrm{i} ; \mathrm{GLE})} \sqrt{\frac{\mathrm{QME}}{\mathrm{r}}}}{\mathrm{m}} \times 100$, em que $\mathrm{q}_{\alpha(\mathrm{i} ; \mathrm{GLE})}$

é o valor crítico do teste de Tukey em nível $\alpha$ de probabilidade de erro $(\alpha=0,05$, nesse estudo), i é o número de tratamentos, GLE é o número de graus de liberdade do erro, ou seja, (i-1)(r-1) para o delineamento blocos ao acaso, QME é o quadrado médio do erro, r é o número de repetições e m é a média do experimento. Substituindo a expressão do coeficiente de variação

experimental $\left(\mathrm{CV}=\frac{\sqrt{\mathrm{QME}}}{\mathrm{m}} \times 100\right), \quad \mathrm{em}$ percentagem, na expressão para o cálculo de d e isolando $r$, têm-se $r=\left(\frac{\mathrm{q}_{\alpha(\mathrm{i} ; \mathrm{GLE})} \mathrm{CV}}{\mathrm{d}}\right)^{2}$. Neste estudo, o CV é expresso em percentagem e corresponde ao $\mathrm{CV}_{\mathrm{Xo}}$, pois esse é o $\mathrm{CV}$ esperado para o experimento com o tamanho ótimo de parcela (Xo) determinado. A seguir, a partir do $\mathrm{CV}_{\mathrm{Xo}}$ de cada caractere (MVV, MVPASV e MVPA), determinou-se o número de repetições (r), por processoiterativo atéa convergência, para experimentos no delineamento blocos ao acaso, em cenários formados pelas combinações de i (i=3, 4, ..., 50) e d (d=10\%, 13\%, ..., 40\%). Menores valores de d indicam maior precisão experimental, ou seja, menores diferenças entre médias de tratamentos serão consideradas significativas e vice-versa. As análises estatísticas foram realizadas com auxílio do aplicativo Microsoft Office Excel ${ }^{\circledR}$ e do software R (R DEVELOPMENT CORE TEAM, 2014).

\section{RESULTADOS E DISCUSSÃO}

Em relação aos dados de massa verde de vagens (MVV, em gramas $\mathrm{m}^{-2}$ ), massa verde de parte aérea sem vagens (MVPASV, em gramas $\mathrm{m}^{-2}$ ) e massa verde de parte aérea (MVPA=MVV+MVPASV, em gramas $\mathrm{m}^{-2}$ ) de feijão de porco (Canavalia ensiformis), houve variabilidade das estimativas do coeficiente de autocorrelação espacial de primeira ordem $(\rho)$, da variância $\left(\mathrm{s}^{2}\right)$, da média $(\mathrm{m})$ e do coeficiente de variação do ensaio $(\mathrm{CV})$, entre os seis ensaios de uniformidade (Tabela 1). Consequentemente, as estimativas do tamanho ótimo de parcela (Xo) e do coeficiente de variação no tamanho ótimo de parcela $\left(\mathrm{CV}_{\mathrm{Xo}}\right)$ também apresentaram variabilidade. A variabilidade das estatísticas $\rho, \mathrm{s}^{2}, \mathrm{~m}, \mathrm{CV}$, Xo e $\mathrm{CV}_{\text {Xo }}$ é particularmente importante para o estudo do dimensionamento do tamanho de parcela e do número de repetições, por incluir cenários extremos e refletir condições reais de áreas de campo. As estatísticas $\rho, \mathrm{s}^{2}, \mathrm{~m}, \mathrm{CV}$, Xo e $\mathrm{CV}_{\mathrm{Xo}}$ apresentaram boa aderência à distribuição normal $(\mathrm{P} \geq 0,808$ para $\mathrm{MVV}$, $\mathrm{P} \geq 0,698$ para MVPASV e $\mathrm{P} \geq 0,725$ para MVPA), de acordo com o teste de Kolmogorov-Smirnov, o que indica que as inferências, com base na média dos seis ensaios, são adequadas.

$\mathrm{Na}$ área onde foram avaliadas as 150 unidades experimentais básicas (UEB), aos 199 dias após a semeadura (DAS), as médias de MVV (321,26 gramas $\mathrm{m}^{-2}$ ) e de MVPASV (2.841,38 gramas $\mathrm{m}^{-2}$ ), representaram, respectivamente, $10,16 \%$ e $89,84 \%$, da MVPA (3.162,64 gramas $\mathrm{m}^{-2}$ ) de feijão de porco (Tabela 1). Essa produção de massa verde de parte aérea de feijão de porco foi superior as verificadas por TEIXEIRA et al. (2008), que obtiveram 13.833 $\mathrm{kg} \mathrm{ha}^{-1}$, aos 119 DAS, quando as plantas estavam no florescimento. Também foi superior à obtida por CARNEIRO et al. (2008) (14.690kg ha-1, aos 121 DAS na fase de florescimento) e por CARVALHO et al. (2013) (média de $8.116 \mathrm{~kg} \mathrm{ha}^{-1}$, aos 91 DAS em 2009 e aos 90 DAS em 2010 com 50\% das plantas em floração). A maior produção, obtida neste estudo, pode estar relacionada ao maior período entre a 
Tabela 1 - Coeficiente de autocorrelação espacial de primeira ordem $(\rho)$, variância $\left(\mathrm{s}^{2}\right)$, média (m), coeficiente de variação do ensaio (CV, em $\%)$, tamanho ótimo de parcela $\left(\mathrm{Xo}\right.$, em $\mathrm{m}^{2}$ ) e coeficiente de variação no tamanho ótimo de parcela $\left(\mathrm{CV}_{\mathrm{Xo}}\right.$, em \%), para a massa verde de vagens (MVV, em gramas $\mathrm{m}^{-2}$ ), a massa verde de parte aérea sem vagens (MVPASV, em gramas $\mathrm{m}^{-2}$ ) e a massa verde de parte aérea (MVPA=MVV+MVPASV, em gramas $\mathrm{m}^{-2}$ ) de feijão de porco (Canavalia ensiformis), em seis ensaios de uniformidade.

\begin{tabular}{|c|c|c|c|c|c|c|}
\hline Ensaio $^{(1)}$ e estatística & $\rho$ & $s^{2}$ & $\mathrm{~m}$ & $\mathrm{CV}(\%)$ & $\mathrm{Xo}\left(\mathrm{m}^{2}\right)$ & $\mathrm{CV}_{\mathrm{Xo}}(\%)$ \\
\hline & \multicolumn{6}{|c|}{----------------------------------Massa verde de vagens (MVV, em gramas $\mathrm{m}^{-2}$ )-- } \\
\hline 1 & 0,04 & $27.452,79$ & 244,04 & 67,89 & 9,73 & 21,75 \\
\hline 2 & 0,39 & $42.235,94$ & 489,76 & 41,96 & 6,67 & 14,92 \\
\hline 3 & 0,18 & $22.920,16$ & 398,36 & 38,00 & 6,54 & 14,61 \\
\hline 4 & 0,43 & $34.371,61$ & 177,24 & 104,60 & 12,11 & 27,09 \\
\hline 5 & 0,18 & $28.064,33$ & 252,60 & 66,32 & 9,48 & 21,19 \\
\hline 6 & $-0,14$ & $23.734,84$ & 365,56 & 42,14 & 7,04 & 15,73 \\
\hline Mínimo & $-0,14$ & $22.920,16$ & 177,24 & 38,00 & 6,54 & 14,61 \\
\hline Máximo & 0,43 & $42.235,94$ & 489,76 & 104,60 & 12,11 & 27,09 \\
\hline Média ${ }^{(2)}$ & $0,18 \mathrm{a}$ & $29.796,61 \mathrm{~b}$ & $321,26 \mathrm{c}$ & $60,15 \mathrm{a}$ & $8,59 \mathrm{a}$ & $19,22 \mathrm{a}$ \\
\hline Desvio padrão & 0,22 & $7.323,83$ & 116,38 & 25,37 & 2,23 & 4,98 \\
\hline Coeficiente de variação (\%) & 118,15 & 24,58 & 36,23 & 42,18 & 25,92 & 25,92 \\
\hline \multirow[t]{2}{*}{ Valor-p ${ }^{(3)}$} & 0,995 & 0,811 & 0,928 & 0,808 & 0,820 & 0,820 \\
\hline & & Massa verde de pa & rea sem vag & VPASV, & $\left.\operatorname{mas} \mathrm{m}^{-2}\right)$ & \\
\hline 1 & 0,19 & $911.520,08$ & $2.654,92$ & 35,96 & 6,29 & 14,07 \\
\hline 2 & 0,01 & $1.298 .204,18$ & $3.000,48$ & 37,97 & 6,61 & 14,77 \\
\hline 3 & $-0,15$ & $920.379,84$ & $2.894,52$ & 33,14 & 5,99 & 13,39 \\
\hline 4 & $-0,42$ & $508.504,17$ & $2.709,40$ & 26,32 & 4,85 & 10,83 \\
\hline 5 & $-0,17$ & $988.417,89$ & $2.906,68$ & 34,20 & 6,10 & 13,65 \\
\hline 6 & 0,03 & $1.440 .455,96$ & $2.882,28$ & 41,64 & 7,02 & 15,71 \\
\hline Mínimo & $-0,42$ & $508.504,17$ & $2.654,92$ & 26,32 & 4,85 & 10,83 \\
\hline Máximo & 0,19 & $1.440 .455,96$ & $3.000,48$ & 41,64 & 7,02 & 15,71 \\
\hline Média ${ }^{(2)}$ & $-0,09$ a & $1.011 .247,02 \mathrm{a}$ & $2.841,38 \mathrm{~b}$ & $34,87 \mathrm{~b}$ & $6,14 b$ & $13,74 \mathrm{~b}$ \\
\hline Desvio padrão & 0,21 & $328.036,15$ & 131,35 & 5,16 & 0,74 & 1,65 \\
\hline Coeficiente de variação (\%) & $-244,22$ & 32,44 & 4,62 & 14,80 & 12,01 & 12,01 \\
\hline \multirow[t]{2}{*}{ Valor-p ${ }^{(3)}$} & 0,989 & 0,947 & 0,698 & 0,967 & 0,848 & 0,848 \\
\hline & \multicolumn{6}{|c|}{-----------Massa verde de parte aérea (MVPA=MVV+MVPASV, em gramas $\mathrm{m}^{-2}$ ) } \\
\hline 1 & 0,16 & $955.841,21$ & $2.898,96$ & 33,72 & 6,05 & 13,54 \\
\hline 2 & 0,02 & $1.488 .741,19$ & $3.490,24$ & 34,96 & 6,25 & 13,98 \\
\hline 3 & $-0,18$ & $933.679,94$ & $3.292,88$ & 29,34 & 5,50 & 12,30 \\
\hline 4 & $-0,34$ & $468.289,74$ & $2.886,64$ & 23,71 & 4,63 & 10,35 \\
\hline 5 & $-0,15$ & $1.181 .183,88$ & $3.159,28$ & 34,40 & 6,14 & 13,73 \\
\hline 6 & 0,04 & $1.480 .424,89$ & $3.247,84$ & 37,46 & 6,54 & 14,63 \\
\hline Mínimo & $-0,34$ & $468.289,74$ & $2.886,64$ & 23,71 & 4,63 & 10,35 \\
\hline Máximo & 0,16 & $1.488 .741,19$ & $3.490,24$ & 37,46 & 6,54 & 14,63 \\
\hline Média ${ }^{(2)}$ & $-0,08 \mathrm{a}$ & $1.084 .693,47 \mathrm{a}$ & $3.162,64 \mathrm{a}$ & $32,27 \mathrm{c}$ & $5,85 \mathrm{c}$ & $13,09 \mathrm{c}$ \\
\hline Desvio padrão & 0,18 & $386.918,56$ & 235,48 & 4,95 & 0,69 & 1,54 \\
\hline Coeficiente de variação (\%) & $-235,48$ & 35,67 & 7,45 & 15,36 & 11,80 & 11,80 \\
\hline Valor-p ${ }^{(3)}$ & 0,971 & 0,989 & 0,967 & 0,725 & 0,730 & 0,730 \\
\hline
\end{tabular}

(1) Cada ensaio de uniformidade de tamanho $5 \mathrm{~m} \times 5 \mathrm{~m}\left(25 \mathrm{~m}^{2}\right)$ foi dividido em 25 unidades experimentais básicas de $1 \mathrm{~m} \times 1 \mathrm{~m}\left(1 \mathrm{~m}^{2}\right)$, formando uma matriz de cinco linhas e cinco colunas. ${ }^{(2)}$ Para cada estatística $\left(\rho, \mathrm{s}^{2}, \mathrm{~m}, \mathrm{CV}, \mathrm{Xo}\right.$ e $\left.\mathrm{CV}_{\mathrm{Xo}}\right)$, as médias não seguidas por mesma letra na coluna (comparação de médias entre caracteres) diferem a $5 \%$ de probabilidade pelo teste t de Student (unilateral) para amostras dependentes, com 5 graus de liberdade. ${ }^{(3)}$ Teste de normalidade de Kolmogorov-Smirnov.

semeadura e o momento de mensuração da massa verde de parte aérea (199 DAS). Por outro lado, a produção de massa verde de parte aérea foi inferior à produção de $78.500 \mathrm{~kg} \mathrm{ha}^{-1}$, obtida aos $138 \mathrm{DAS}$, quando as plantas estavam no estádio de grão leitoso (ALMEIDA \& CAMARA, 2011). A boa produção de massa verde de parte aérea, aliada ao elevado conjunto de dados (150UEB), distribuídos em seis 
ensaios de uniformidade, e ao cenário de ampla variabilidade conferem credibilidade ao estudo do dimensionamento do tamanho ótimo de parcela e do número de repetições.

Em relação ao coeficiente de autocorrelação espacial de primeira ordem ( $\rho$ ), não houve diferença significativa entre os caracteres MVV, MVPASV e MVPA (Tabela 1). Assim, o valor médio $(\rho=0,0033)$ é adequado para representar os três caracteres. Devese interpretar que, para valores fixos de $\mathrm{s}^{2} \mathrm{e} \mathrm{m}$, quanto mais próximo de 1 (autocorrelação espacial positiva) ou de -1 (autocorrelação espacial negativa) for o $\rho$, maior a dependência entre os valores das unidades experimentais básicas adjacentes e, consequentemente, menor será a estimativa de Xo pela equação de PARANAÍBA et al. (2009). Por outro lado, quando $\rho$ for igual a zero, neste estudo $\rho=0,0033$, há ausência de autocorrelação espacial e, por consequência, o Xo é máximo, pois as UEBs seriam independentes.

De maneira geral, para os caracteres MVV, MVPASV e MVPA, nessa ordem, houve aumento da variância $\left(\mathrm{s}^{2}\right)$ e da média $(\mathrm{m})$ e diminuição do coeficiente de variação do ensaio (CV) (Tabela 1). Com isso, as estimativas do tamanho ótimo de parcela (Xo) e do coeficiente de variação no tamanho ótimo de parcela $\left(\mathrm{CV}_{\mathrm{Xo}}\right)$ diferiram entre os caracteres. Assim, pode-se inferir que, entre os caracteres de feijão de porco, $\mathrm{Xo}$ e $\mathrm{CV}_{\mathrm{Xo}}$ decrescem na seguinte ordem: massa verde de vagens $\left(\mathrm{Xo}=8,59 \mathrm{~m}^{2}\right.$, $\mathrm{CV}_{\mathrm{Xo}}=19,22 \%$ ), massa verde de parte aérea sem vagens $\left(\mathrm{Xo}=6,14 \mathrm{~m}^{2}, \mathrm{CV}_{\mathrm{Xo}_{0}}=13,74 \%\right)$ e massa verde de parte aérea $\left(\mathrm{Xo}=5,85 \mathrm{~m}^{2}, \mathrm{CV}_{\mathrm{Xo}}=13,09 \%\right)$. Esses tamanhos de parcela foram inferiores aos utilizados por CARNEIRO et al. (2008), TEIXEIRA et al. (2008), TEIXEIRA et al. (2010), ALMEIDA \& CAMARA (2011), CESAR et al. (2011), CARDOSO et al. (2013) e CARVALHO et al. (2013), o que sugere confiabilidade nas informações publicadas. Por outro lado, esses tamanhos foram maiores que o tamanho de parcela de $2 \mathrm{~m}^{2}$ utilizado por MAIA et al. (2013), em estudo de densidades de semeadura do feijão de porco. A comparação entre os tamanhos ótimos de parcela, obtidos nesse estudo, com os tamanhos de parcela utilizados nos trabalhos supracitados deve ser vista com cautela, pois há diferenças quanto à área da parcela efetivamente utilizada para as avaliações, ao manejo, às variáveis analisadas e ainda à presença de outras culturas, juntamente com o feijão de porco. Não foram encontrados estudos de tamanho ótimo de parcela para avaliar a MVV, MVPASV e MVPA de feijão de porco para serem comparados com os obtidos neste estudo. Em nabo forrageiro, cultura de cobertura de solo, como o feijão de porco, o tamanho ótimo de parcela, para avaliar a massa verde, determinado por CARGNELUTTI FILHO et al. (2011), foi de $1,20 \mathrm{~m}^{2}$.

O número de repetições, para experimentos no delineamento blocos ao acaso (DBA), em cenários formados pelas combinações de i tratamentos ( $\mathrm{i}=3$, $4, \ldots, 50)$ e d diferenças mínimas entre médias de tratamentos a serem detectadas como significativas a $5 \%$ de probabilidade, pelo teste de Tukey, expressas em percentagem da média do experimento $(\mathrm{d}=10 \%$, $13 \%, \ldots, 40 \%)$, para avaliar a massa verde de vagens de feijão de porco, oscilou entre 4,13 (3 tratamentos e $\mathrm{d}=40 \%$ ) e 117,90 (50 tratamentos e $\mathrm{d}=10 \%$ ) (Tabela 2), a massa verde de parte aérea sem vagens variou entre 2,90 (3 tratamentos e $\mathrm{d}=40 \%$ ) e 60,32 (50 tratamentos e $\mathrm{d}=10 \%$ ) (Tabela 3 ), e a massa verde de parte aérea oscilou na faixa de 2,73 (3 tratamentos e d=40\%) e 54,76 (50 tratamentos e d=10\%) (Tabela 4). Portanto, mesmo com coeficientes de variação de 19,22\%, $13,74 \%$ e $13,09 \%$, respectivamente, para os caracteres MVV, MVPASV e MVPA, classificados como médios (PIMENTEL-GOMES, 1990), obter precisão de $10 \%$ (maior precisão) é impraticável, pelo elevado número de repetições necessário. Não cabe aqui o julgamento de qual a precisão que deve ser adotada, ficando essa tarefa ao usuário dessas informações, que, com base na variável a ser mensurada e no respectivo $\mathrm{CV}_{\mathrm{Xo}}$, poderá estabelecer a relação entre i, d e número de repetições, possível de ser realizada.

Independentemente do caractere (MVV, MVPASV e MVPA), para valores fixos de d e $\mathrm{CV}_{\mathrm{Xo}}$, há aumento do número de repetições (r) com o acréscimo do número de tratamentos (Tabelas 2, 3 e 4). Como esperado, para valores fixos de i e d, quanto maior o $\mathrm{CV}_{\mathrm{Xo}}$, mais repetições são necessárias. Então, o número de repetições para avaliar a MVV, MVPASV e MVPA é decrescente, nessa ordem. Assim, por exemplo, para avaliar $\mathrm{i}=50 \mathrm{e} \mathrm{d}=40 \%$, precisariam 7,51 repetições para MVV, 3,94 repetições para MVPASV e 3,59 repetições para MVPA.

Na prática, não é possível realizar 7,51, 3,94 ou 3,59 repetições. Então, fixando-se $r$ igual a quatro repetições, conforme utilizado nos experimentos realizados, no delineamento blocos ao acaso, por TEIXEIRA et al. (2008), TEIXEIRA et al. (2010), ALMEIDA \& CAMARA (2011), CESAR et al. (2011), CARVALHO et al. (2013) e MAIA et al. (2013), a diferença mínima significativa (d) do teste de Tukey, expressa em percentagem da média do experimento, é estimada pela expressão:

$$
\mathrm{d}=\frac{\mathrm{q}_{\alpha(\mathrm{i} ; \mathrm{GLE})} \mathrm{CV}}{\sqrt{\mathrm{r}}} \cdot \text { Assim, com } 50
$$


Tabela 2 - Número de repetições, para experimentos no delineamento blocos ao acaso, em cenários formados pelas combinações de i tratamentos $(i=3,4, \ldots, 50)$ e d diferenças mínimas entre médias de tratamentos a serem detectadas como significativas a $5 \%$ de probabilidade, pelo teste de Tukey, expressas em percentagem da média do experimento ( $\mathrm{d}=10 \%, 13 \%, \ldots, 40 \%)$, para avaliar a massa verde de vagens de feijão de porco (Canavalia ensiformis), a partir de tamanho ótimo de parcela $\left(\mathrm{Xo}=8,59 \mathrm{~m}^{2}\right) \mathrm{e}$ coeficiente de variação no tamanho ótimo de parcela $\left(\mathrm{CV}_{\mathrm{Xo}}=19,22 \%\right)$.

\begin{tabular}{|c|c|c|c|c|c|c|c|c|c|c|c|}
\hline $\mathrm{i}$ & $10 \%$ & $13 \%$ & $16 \%$ & $19 \%$ & $22 \%$ & $25 \%$ & $28 \%$ & $31 \%$ & $34 \%$ & $37 \%$ & $40 \%$ \\
\hline 3 & 42,09 & 25,53 & 17,39 & 12,79 & 9,94 & 8,07 & 6,77 & 5,84 & 5,14 & 4,59 & 4,13 \\
\hline 4 & 49,89 & 30,00 & 20,20 & 14,67 & 11,25 & 9,00 & 7,43 & 6,29 & 5,46 & 4,82 & 4,32 \\
\hline 5 & 55,90 & 33,46 & 22,41 & 16,18 & 12,32 & 9,77 & 8,00 & 6,72 & 5,77 & 5,04 & 4,48 \\
\hline 6 & 60,78 & 36,29 & 24,24 & 17,43 & 13,21 & 10,43 & 8,49 & 7,10 & 6,06 & 5,26 & 4,65 \\
\hline 7 & 64,91 & 38,69 & 25,79 & 18,50 & 13,98 & 11,00 & 8,93 & 7,43 & 6,31 & 5,47 & 4,80 \\
\hline 8 & 68,48 & 40,78 & 27,14 & 19,43 & 14,66 & 11,51 & 9,31 & 7,73 & 6,55 & 5,65 & 4,95 \\
\hline 9 & 71,64 & 42,62 & 28,33 & 20,26 & 15,26 & 11,96 & 9,66 & 8,00 & 6,76 & 5,82 & 5,08 \\
\hline 10 & 74,46 & 44,27 & 29,40 & 21,01 & 15,81 & 12,37 & 9,98 & 8,25 & 6,96 & 5,98 & 5,21 \\
\hline 11 & 77,01 & 45,76 & 30,38 & 21,69 & 16,30 & 12,74 & 10,27 & 8,48 & 7,14 & 6,12 & 5,32 \\
\hline 12 & 79,34 & 47,13 & 31,27 & 22,31 & 16,76 & 13,09 & 10,53 & 8,69 & 7,31 & 6,26 & 5,44 \\
\hline 13 & 81,49 & 48,39 & 32,09 & 22,88 & 17,18 & 13,40 & 10,78 & 8,88 & 7,47 & 6,38 & 5,54 \\
\hline 14 & 83,48 & 49,56 & 32,85 & 23,41 & 17,57 & 13,70 & 11,01 & 9,07 & 7,61 & 6,50 & 5,64 \\
\hline 15 & 85,33 & 50,64 & 33,56 & 23,91 & 17,93 & 13,98 & 11,23 & 9,24 & 7,75 & 6,62 & 5,73 \\
\hline 16 & 87,07 & 51,66 & 34,23 & 24,38 & 18,28 & 14,24 & 11,43 & 9,40 & 7,88 & 6,72 & 5,82 \\
\hline 17 & 88,70 & 52,62 & 34,85 & 24,82 & 18,60 & 14,48 & 11,62 & 9,55 & 8,01 & 6,82 & 5,90 \\
\hline 18 & 90,24 & 53,52 & 35,44 & 25,23 & 18,90 & 14,72 & 11,80 & 9,70 & 8,12 & 6,92 & 5,98 \\
\hline 19 & 91,69 & 54,38 & 36,01 & 25,62 & 19,19 & 14,94 & 11,98 & 9,84 & 8,24 & 7,01 & 6,06 \\
\hline 20 & 93,07 & 55,19 & 36,54 & 26,00 & 19,47 & 15,15 & 12,14 & 9,97 & 8,34 & 7,10 & 6,13 \\
\hline 21 & 94,39 & 55,97 & 37,04 & 26,35 & 19,73 & 15,35 & 12,30 & 10,09 & 8,45 & 7,19 & 6,20 \\
\hline 22 & 95,64 & 56,70 & 37,53 & 26,69 & 19,98 & 15,54 & 12,45 & 10,21 & 8,54 & 7,27 & 6,27 \\
\hline 23 & 96,84 & 57,41 & 37,99 & 27,02 & 20,22 & 15,72 & 12,59 & 10,33 & 8,64 & 7,34 & 6,33 \\
\hline 24 & 97,99 & 58,09 & 38,43 & 27,33 & 20,45 & 15,90 & 12,73 & 10,44 & 8,73 & 7,42 & 6,39 \\
\hline 25 & 99,09 & 58,74 & 38,86 & 27,63 & 20,67 & 16,07 & 12,86 & 10,55 & 8,82 & 7,49 & 6,45 \\
\hline 26 & 100,15 & 59,36 & 39,27 & 27,92 & 20,89 & 16,23 & 12,99 & 10,65 & 8,90 & 7,56 & 6,51 \\
\hline 27 & 101,17 & 59,96 & 39,66 & 28,20 & 21,09 & 16,39 & 13,12 & 10,75 & 8,98 & 7,63 & 6,57 \\
\hline 28 & 102,16 & 60,54 & 40,04 & 28,46 & 21,29 & 16,54 & 13,24 & 10,84 & 9,06 & 7,69 & 6,62 \\
\hline 29 & 103,11 & 61,10 & 40,41 & 28,72 & 21,48 & 16,69 & 13,35 & 10,94 & 9,13 & 7,75 & 6,67 \\
\hline 30 & 104,03 & 61,64 & 40,76 & 28,97 & 21,66 & 16,83 & 13,46 & 11,03 & 9,21 & 7,81 & 6,72 \\
\hline 31 & 104,91 & 62,16 & 41,11 & 29,21 & 21,84 & 16,97 & 13,57 & 11,11 & 9,28 & 7,87 & 6,77 \\
\hline 32 & 105,77 & 62,67 & 41,44 & 29,45 & 22,02 & 17,10 & 13,68 & 11,20 & 9,35 & 7,93 & 6,82 \\
\hline 33 & 106,61 & 63,16 & 41,76 & 29,67 & 22,19 & 17,23 & 13,78 & 11,28 & 9,42 & 7,99 & 6,87 \\
\hline 34 & 107,42 & 63,64 & 42,08 & 29,89 & 22,35 & 17,35 & 13,88 & 11,36 & 9,48 & 8,04 & 6,91 \\
\hline 35 & 108,20 & 64,10 & 42,38 & 30,11 & 22,51 & 17,47 & 13,97 & 11,44 & 9,54 & 8,09 & 6,96 \\
\hline 36 & 108,97 & 64,55 & 42,68 & 30,32 & 22,66 & 17,59 & 14,07 & 11,51 & 9,61 & 8,15 & 7,00 \\
\hline 37 & 109,71 & 64,99 & 42,96 & 30,52 & 22,81 & 17,71 & 14,16 & 11,59 & 9,67 & 8,20 & 7,04 \\
\hline 38 & 110,43 & 65,42 & 43,24 & 30,72 & 22,96 & 17,82 & 14,25 & 11,66 & 9,73 & 8,24 & 7,09 \\
\hline 39 & 111,14 & 65,83 & 43,52 & 30,91 & 23,10 & 17,93 & 14,33 & 11,73 & 9,78 & 8,29 & 7,13 \\
\hline 40 & 111,83 & 66,24 & 43,78 & 31,10 & 23,24 & 18,04 & 14,42 & 11,80 & 9,84 & 8,34 & 7,16 \\
\hline 41 & 112,50 & 66,63 & 44,04 & 31,28 & 23,38 & 18,14 & 14,50 & 11,86 & 9,89 & 8,38 & 7,20 \\
\hline 42 & 113,15 & 67,02 & 44,30 & 31,46 & 23,51 & 18,24 & 14,58 & 11,93 & 9,95 & 8,43 & 7,24 \\
\hline 43 & 113,79 & 67,40 & 44,55 & 31,64 & 23,64 & 18,34 & 14,66 & 11,99 & 10,00 & 8,47 & 7,28 \\
\hline 44 & 114,42 & 67,77 & 44,79 & 31,81 & 23,77 & 18,44 & 14,74 & 12,05 & 10,05 & 8,51 & 7,31 \\
\hline 45 & 115,03 & 68,13 & 45,03 & 31,97 & 23,89 & 18,54 & 14,81 & 12,11 & 10,10 & 8,56 & 7,35 \\
\hline 46 & 115,63 & 68,48 & 45,26 & 32,14 & 24,01 & 18,63 & 14,88 & 12,17 & 10,15 & 8,60 & 7,38 \\
\hline 47 & 116,21 & 68,82 & 45,48 & 32,30 & 24,13 & 18,72 & 14,96 & 12,23 & 10,20 & 8,64 & 7,42 \\
\hline 48 & 116,78 & 69,16 & 45,71 & 32,46 & 24,25 & 18,81 & 15,03 & 12,29 & 10,24 & 8,68 & 7,45 \\
\hline 49 & 117,35 & 69,49 & 45,92 & 32,61 & 24,36 & 18,90 & 15,10 & 12,35 & 10,29 & 8,72 & 7,48 \\
\hline 50 & 117,90 & 69,82 & 46,14 & 32,76 & 24,47 & 18,98 & 15,16 & 12,40 & 10,34 & 8,75 & 7,51 \\
\hline
\end{tabular}


Tabela 3 - Número de repetições, para experimentos no delineamento blocos ao acaso, em cenários formados pelas combinações de i tratamentos $(\mathrm{i}=3,4, \ldots, 50)$ e d diferenças mínimas entre médias de tratamentos a serem detectadas como significativas a 5\% de probabilidade, pelo teste de Tukey, expressas em percentagem da média do experimento ( $\mathrm{d}=10 \%, 13 \%, \ldots, 40 \%)$, para avaliar a massa verde de parte aérea sem vagens de feijão de porco (Canavalia ensiformis), a partir de tamanho ótimo de parcela $\left(\mathrm{Xo}=6,14 \mathrm{~m}^{2}\right)$ e coeficiente de variação no tamanho ótimo de parcela $\left(\mathrm{CV}_{\mathrm{Xo}_{0}}=13,74 \%\right)$.

\begin{tabular}{|c|c|c|c|c|c|c|c|c|c|c|c|}
\hline $\mathrm{i}$ & $10 \%$ & $13 \%$ & $16 \%$ & $19 \%$ & $22 \%$ & $25 \%$ & $28 \%$ & $31 \%$ & $34 \%$ & $37 \%$ & $40 \%$ \\
\hline 3 & 22,26 & 13,81 & 9,67 & 7,33 & 5,88 & 4,93 & 4,27 & 3,66 & 2,99 & 2,95 & 2,90 \\
\hline 4 & 26,07 & 15,91 & 10,91 & 8,10 & 6,37 & 5,23 & 4,45 & 3,86 & 3,43 & 3,10 & 2,90 \\
\hline 5 & 29,03 & 17,57 & 11,93 & 8,76 & 6,80 & 5,52 & 4,62 & 3,99 & 3,52 & 3,15 & 2,91 \\
\hline 6 & 31,46 & 18,95 & 12,80 & 9,33 & 7,19 & 5,78 & 4,80 & 4,11 & 3,59 & 3,20 & 2,91 \\
\hline 7 & 33,52 & 20,12 & 13,54 & 9,82 & 7,53 & 6,01 & 4,97 & 4,22 & 3,66 & 3,24 & 2,93 \\
\hline 8 & 35,31 & 21,15 & 14,19 & 10,26 & 7,83 & 6,23 & 5,13 & 4,33 & 3,74 & 3,30 & 2,96 \\
\hline 9 & 36,89 & 22,06 & 14,77 & 10,65 & 8,11 & 6,43 & 5,27 & 4,43 & 3,82 & 3,35 & 2,99 \\
\hline 10 & 38,31 & 22,88 & 15,29 & 11,01 & 8,36 & 6,61 & 5,40 & 4,53 & 3,89 & 3,40 & 3,02 \\
\hline 11 & 39,59 & 23,63 & 15,77 & 11,33 & 8,59 & 6,78 & 5,53 & 4,62 & 3,96 & 3,45 & 3,06 \\
\hline 12 & 40,77 & 24,31 & 16,21 & 11,63 & 8,81 & 6,94 & 5,64 & 4,71 & 4,02 & 3,50 & 3,09 \\
\hline 13 & 41,85 & 24,94 & 16,61 & 11,91 & 9,01 & 7,09 & 5,75 & 4,79 & 4,08 & 3,54 & 3,13 \\
\hline 14 & 42,86 & 25,52 & 16,99 & 12,17 & 9,19 & 7,22 & 5,86 & 4,87 & 4,14 & 3,59 & 3,16 \\
\hline 15 & 43,79 & 26,07 & 17,34 & 12,41 & 9,37 & 7,35 & 5,96 & 4,95 & 4,20 & 3,63 & 3,19 \\
\hline 16 & 44,67 & 26,58 & 17,67 & 12,64 & 9,53 & 7,47 & 6,05 & 5,02 & 4,25 & 3,67 & 3,22 \\
\hline 17 & 45,49 & 27,06 & 17,98 & 12,86 & 9,69 & 7,59 & 6,14 & 5,09 & 4,31 & 3,71 & 3,25 \\
\hline 18 & 46,27 & 27,51 & 18,28 & 13,06 & 9,83 & 7,70 & 6,22 & 5,15 & 4,36 & 3,75 & 3,28 \\
\hline 19 & 47,01 & 27,94 & 18,56 & 13,26 & 9,97 & 7,81 & 6,30 & 5,21 & 4,41 & 3,79 & 3,31 \\
\hline 20 & 47,71 & 28,35 & 18,82 & 13,44 & 10,11 & 7,91 & 6,38 & 5,27 & 4,45 & 3,83 & 3,34 \\
\hline 21 & 48,38 & 28,74 & 19,08 & 13,62 & 10,24 & 8,00 & 6,45 & 5,33 & 4,50 & 3,86 & 3,37 \\
\hline 22 & 49,01 & 29,11 & 19,32 & 13,78 & 10,36 & 8,09 & 6,52 & 5,39 & 4,54 & 3,90 & 3,40 \\
\hline 23 & 49,62 & 29,47 & 19,55 & 13,95 & 10,48 & 8,18 & 6,59 & 5,44 & 4,58 & 3,93 & 3,42 \\
\hline 24 & 50,20 & 29,81 & 19,77 & 14,10 & 10,59 & 8,27 & 6,65 & 5,49 & 4,62 & 3,96 & 3,45 \\
\hline 25 & 50,76 & 30,14 & 19,98 & 14,25 & 10,70 & 8,35 & 6,72 & 5,54 & 4,66 & 3,99 & 3,47 \\
\hline 26 & 51,30 & 30,45 & 20,19 & 14,39 & 10,80 & 8,43 & 6,78 & 5,59 & 4,70 & 4,02 & 3,50 \\
\hline 27 & 51,82 & 30,76 & 20,39 & 14,53 & 10,90 & 8,50 & 6,84 & 5,63 & 4,74 & 4,05 & 3,52 \\
\hline 28 & 52,32 & 31,05 & 20,58 & 14,66 & 11,00 & 8,58 & 6,89 & 5,68 & 4,77 & 4,08 & 3,54 \\
\hline 29 & 52,80 & 31,33 & 20,76 & 14,79 & 11,09 & 8,65 & 6,95 & 5,72 & 4,81 & 4,11 & 3,56 \\
\hline 30 & 53,27 & 31,61 & 20,94 & 14,92 & 11,19 & 8,72 & 7,00 & 5,76 & 4,84 & 4,13 & 3,59 \\
\hline 31 & 53,72 & 31,87 & 21,11 & 15,04 & 11,27 & 8,78 & 7,05 & 5,80 & 4,87 & 4,16 & 3,61 \\
\hline 32 & 54,15 & 32,13 & 21,28 & 15,15 & 11,36 & 8,85 & 7,10 & 5,84 & 4,90 & 4,19 & 3,63 \\
\hline 33 & 54,58 & 32,38 & 21,44 & 15,27 & 11,44 & 8,91 & 7,15 & 5,88 & 4,94 & 4,21 & 3,65 \\
\hline 34 & 54,99 & 32,62 & 21,60 & 15,38 & 11,52 & 8,97 & 7,20 & 5,92 & 4,97 & 4,24 & 3,67 \\
\hline 35 & 55,39 & 32,85 & 21,75 & 15,48 & 11,60 & 9,03 & 7,25 & 5,96 & 5,00 & 4,26 & 3,69 \\
\hline 36 & 55,78 & 33,08 & 21,90 & 15,59 & 11,68 & 9,09 & 7,29 & 5,99 & 5,02 & 4,28 & 3,71 \\
\hline 37 & 56,15 & 33,30 & 22,05 & 15,69 & 11,75 & 9,15 & 7,34 & 6,03 & 5,05 & 4,31 & 3,73 \\
\hline 38 & 56,52 & 33,52 & 22,19 & 15,79 & 11,83 & 9,20 & 7,38 & 6,06 & 5,08 & 4,33 & 3,74 \\
\hline 39 & 56,88 & 33,73 & 22,33 & 15,89 & 11,90 & 9,26 & 7,42 & 6,10 & 5,11 & 4,35 & 3,76 \\
\hline 40 & 57,23 & 33,93 & 22,46 & 15,98 & 11,97 & 9,31 & 7,46 & 6,13 & 5,13 & 4,37 & 3,78 \\
\hline 41 & 57,57 & 34,13 & 22,59 & 16,07 & 12,03 & 9,36 & 7,50 & 6,16 & 5,16 & 4,39 & 3,80 \\
\hline 42 & 57,91 & 34,33 & 22,72 & 16,16 & 12,10 & 9,41 & 7,54 & 6,19 & 5,18 & 4,41 & 3,81 \\
\hline 43 & 58,23 & 34,52 & 22,85 & 16,25 & 12,16 & 9,46 & 7,58 & 6,22 & 5,21 & 4,43 & 3,83 \\
\hline 44 & 58,55 & 34,71 & 22,97 & 16,34 & 12,23 & 9,51 & 7,62 & 6,25 & 5,23 & 4,45 & 3,85 \\
\hline 45 & 58,86 & 34,89 & 23,09 & 16,42 & 12,29 & 9,56 & 7,66 & 6,28 & 5,26 & 4,47 & 3,86 \\
\hline 46 & 59,16 & 35,07 & 23,20 & 16,50 & 12,35 & 9,60 & 7,69 & 6,31 & 5,28 & 4,49 & 3,88 \\
\hline 47 & 59,46 & 35,25 & 23,32 & 16,58 & 12,41 & 9,65 & 7,73 & 6,34 & 5,30 & 4,51 & 3,89 \\
\hline 48 & 59,75 & 35,42 & 23,43 & 16,66 & 12,47 & 9,69 & 7,76 & 6,37 & 5,33 & 4,53 & 3,91 \\
\hline 49 & 60,04 & 35,58 & 23,54 & 16,74 & 12,52 & 9,74 & 7,80 & 6,39 & 5,35 & 4,55 & 3,92 \\
\hline 50 & 60,32 & 35,75 & 23,65 & 16,81 & 12,58 & 9,78 & 7,83 & 6,42 & 5,37 & 4,56 & 3,94 \\
\hline
\end{tabular}


Tabela 4 - Número de repetições, para experimentos no delineamento blocos ao acaso, em cenários formados pelas combinações de i tratamentos $(\mathrm{i}=3,4, \ldots, 50)$ e d diferenças mínimas entre médias de tratamentos a serem detectadas como significativas a 5\% de probabilidade, pelo teste de Tukey, expressas em percentagem da média do experimento ( $\mathrm{d}=10 \%, 13 \%, \ldots, 40 \%)$, para avaliar a massa verde de parte aérea de feijão de porco (Canavalia ensiformis), a partir de tamanho ótimo de parcela $\left(\mathrm{Xo}=5,85 \mathrm{~m}^{2}\right)$ e coeficiente de variação no tamanho ótimo de parcela $\left(\mathrm{CV}_{\mathrm{Xo}_{\mathrm{O}}}=13,09 \%\right)$.

\begin{tabular}{|c|c|c|c|c|c|c|c|c|c|c|c|}
\hline $\mathrm{i}$ & $10 \%$ & $13 \%$ & $16 \%$ & $19 \%$ & $22 \%$ & $25 \%$ & $28 \%$ & $31 \%$ & $34 \%$ & $37 \%$ & $40 \%$ \\
\hline 3 & 20,35 & 12,69 & 8,92 & 6,80 & 5,50 & 4,63 & 3,97 & 3,33 & 3,23 & 2,98 & 2,73 \\
\hline 4 & 23,77 & 14,55 & 10,02 & 7,47 & 5,90 & 4,87 & 4,15 & 3,64 & 3,27 & 2,99 & 2,73 \\
\hline 5 & 26,43 & 16,04 & 10,92 & 8,05 & 6,27 & 5,11 & 4,31 & 3,73 & 3,31 & 2,99 & 2,74 \\
\hline 6 & 28,62 & 17,27 & 11,69 & 8,55 & 6,61 & 5,33 & 4,45 & 3,82 & 3,35 & 3,01 & 2,74 \\
\hline 7 & 30,49 & 18,33 & 12,36 & 8,99 & 6,91 & 5,54 & 4,59 & 3,91 & 3,41 & 3,04 & 2,76 \\
\hline 8 & 32,10 & 19,26 & 12,94 & 9,38 & 7,18 & 5,73 & 4,73 & 4,01 & 3,48 & 3,08 & 2,77 \\
\hline 9 & 33,53 & 20,08 & 13,46 & 9,73 & 7,42 & 5,90 & 4,85 & 4,10 & 3,54 & 3,12 & 2,79 \\
\hline 10 & 34,82 & 20,82 & 13,93 & 10,05 & 7,64 & 6,06 & 4,97 & 4,18 & 3,60 & 3,16 & 2,82 \\
\hline 11 & 35,98 & 21,49 & 14,36 & 10,34 & 7,85 & 6,21 & 5,07 & 4,26 & 3,65 & 3,20 & 2,85 \\
\hline 12 & 37,04 & 22,11 & 14,75 & 10,61 & 8,04 & 6,35 & 5,18 & 4,33 & 3,71 & 3,24 & 2,88 \\
\hline 13 & 38,02 & 22,67 & 15,12 & 10,86 & 8,22 & 6,48 & 5,27 & 4,40 & 3,76 & 3,28 & 2,90 \\
\hline 14 & 38,93 & 23,20 & 15,46 & 11,09 & 8,38 & 6,60 & 5,36 & 4,47 & 3,81 & 3,31 & 2,93 \\
\hline 15 & 39,78 & 23,69 & 15,78 & 11,31 & 8,54 & 6,72 & 5,45 & 4,54 & 3,86 & 3,35 & 2,95 \\
\hline 16 & 40,58 & 24,16 & 16,07 & 11,51 & 8,69 & 6,82 & 5,53 & 4,60 & 3,91 & 3,39 & 2,98 \\
\hline 17 & 41,32 & 24,59 & 16,36 & 11,71 & 8,83 & 6,93 & 5,61 & 4,66 & 3,95 & 3,42 & 3,01 \\
\hline 18 & 42,03 & 25,00 & 16,62 & 11,89 & 8,96 & 7,03 & 5,68 & 4,72 & 4,00 & 3,45 & 3,03 \\
\hline 19 & 42,70 & 25,39 & 16,87 & 12,06 & 9,09 & 7,12 & 5,75 & 4,77 & 4,04 & 3,48 & 3,06 \\
\hline 20 & 43,33 & 25,76 & 17,11 & 12,23 & 9,21 & 7,21 & 5,82 & 4,82 & 4,08 & 3,52 & 3,08 \\
\hline 21 & 43,93 & 26,11 & 17,34 & 12,39 & 9,32 & 7,29 & 5,89 & 4,87 & 4,12 & 3,55 & 3,10 \\
\hline 22 & 44,51 & 26,45 & 17,56 & 12,54 & 9,43 & 7,38 & 5,95 & 4,92 & 4,16 & 3,58 & 3,12 \\
\hline 23 & 45,06 & 26,77 & 17,77 & 12,68 & 9,54 & 7,46 & 6,01 & 4,97 & 4,19 & 3,60 & 3,15 \\
\hline 24 & 45,59 & 27,08 & 17,97 & 12,82 & 9,64 & 7,53 & 6,07 & 5,01 & 4,23 & 3,63 & 3,17 \\
\hline 25 & 46,10 & 27,38 & 18,16 & 12,96 & 9,74 & 7,60 & 6,13 & 5,06 & 4,26 & 3,66 & 3,19 \\
\hline 26 & 46,58 & 27,66 & 18,35 & 13,09 & 9,83 & 7,68 & 6,18 & 5,10 & 4,30 & 3,69 & 3,21 \\
\hline 27 & 47,05 & 27,94 & 18,53 & 13,21 & 9,92 & 7,74 & 6,23 & 5,14 & 4,33 & 3,71 & 3,23 \\
\hline 28 & 47,51 & 28,20 & 18,70 & 13,33 & 10,01 & 7,81 & 6,28 & 5,18 & 4,36 & 3,74 & 3,25 \\
\hline 29 & 47,94 & 28,46 & 18,87 & 13,45 & 10,09 & 7,87 & 6,33 & 5,22 & 4,39 & 3,76 & 3,27 \\
\hline 30 & 48,37 & 28,71 & 19,03 & 13,56 & 10,17 & 7,94 & 6,38 & 5,26 & 4,42 & 3,78 & 3,29 \\
\hline 31 & 48,77 & 28,95 & 19,18 & 13,67 & 10,25 & 8,00 & 6,43 & 5,29 & 4,45 & 3,81 & 3,31 \\
\hline 32 & 49,17 & 29,18 & 19,33 & 13,77 & 10,33 & 8,05 & 6,47 & 5,33 & 4,48 & 3,83 & 3,32 \\
\hline 33 & 49,55 & 29,40 & 19,48 & 13,88 & 10,41 & 8,11 & 6,52 & 5,36 & 4,51 & 3,85 & 3,34 \\
\hline 34 & 49,93 & 29,62 & 19,62 & 13,98 & 10,48 & 8,17 & 6,56 & 5,40 & 4,53 & 3,87 & 3,36 \\
\hline 35 & 50,29 & 29,83 & 19,76 & 14,07 & 10,55 & 8,22 & 6,60 & 5,43 & 4,56 & 3,89 & 3,38 \\
\hline 36 & 50,64 & 30,04 & 19,90 & 14,17 & 10,62 & 8,27 & 6,64 & 5,46 & 4,58 & 3,91 & 3,39 \\
\hline 37 & 50,98 & 30,24 & 20,03 & 14,26 & 10,69 & 8,32 & 6,68 & 5,49 & 4,61 & 3,93 & 3,41 \\
\hline 38 & 51,32 & 30,44 & 20,16 & 14,35 & 10,75 & 8,37 & 6,72 & 5,52 & 4,63 & 3,95 & 3,42 \\
\hline 39 & 51,64 & 30,63 & 20,28 & 14,44 & 10,82 & 8,42 & 6,76 & 5,55 & 4,66 & 3,97 & 3,44 \\
\hline 40 & 51,96 & 30,82 & 20,40 & 14,52 & 10,88 & 8,47 & 6,79 & 5,58 & 4,68 & 3,99 & 3,46 \\
\hline 41 & 52,27 & 31,00 & 20,52 & 14,60 & 10,94 & 8,52 & 6,83 & 5,61 & 4,70 & 4,01 & 3,47 \\
\hline 42 & 52,57 & 31,17 & 20,64 & 14,69 & 11,00 & 8,56 & 6,86 & 5,64 & 4,73 & 4,03 & 3,49 \\
\hline 43 & 52,87 & 31,35 & 20,75 & 14,76 & 11,06 & 8,60 & 6,90 & 5,67 & 4,75 & 4,05 & 3,50 \\
\hline 44 & 53,15 & 31,52 & 20,86 & 14,84 & 11,11 & 8,65 & 6,93 & 5,69 & 4,77 & 4,06 & 3,51 \\
\hline 45 & 53,44 & 31,68 & 20,97 & 14,92 & 11,17 & 8,69 & 6,97 & 5,72 & 4,79 & 4,08 & 3,53 \\
\hline 46 & 53,71 & 31,84 & 21,08 & 14,99 & 11,22 & 8,73 & 7,00 & 5,75 & 4,81 & 4,10 & 3,54 \\
\hline 47 & 53,98 & 32,00 & 21,18 & 15,07 & 11,28 & 8,77 & 7,03 & 5,77 & 4,83 & 4,11 & 3,56 \\
\hline 48 & 54,25 & 32,16 & 21,28 & 15,14 & 11,33 & 8,81 & 7,06 & 5,80 & 4,85 & 4,13 & 3,57 \\
\hline 49 & 54,51 & 32,31 & 21,38 & 15,21 & 11,38 & 8,85 & 7,09 & 5,82 & 4,87 & 4,15 & 3,58 \\
\hline 50 & 54,76 & 32,46 & 21,48 & 15,27 & 11,43 & 8,89 & 7,12 & 5,84 & 4,89 & 4,16 & 3,59 \\
\hline
\end{tabular}

Ciência Rural, v.44, n.12, dez, 2014. 
tratamentos, para a massa verde de vagens

$\mathrm{d}=\frac{\mathrm{q}_{5 \%(50 ; 150)} \times 19,22}{\sqrt{4}}=\frac{5,7710567 \times 19,22}{\sqrt{4}}=55,48 \%$,

para massa verde de parte aérea sem vagens

$\mathrm{d}=\frac{\mathrm{q}_{5 \%(50 ; 150)} \times 13,74}{\sqrt{4}}=\frac{5,7710567 \times 13,74}{\sqrt{4}}=39,66 \%$

e para massa verde de parte aérea

$\mathrm{d}=\frac{\mathrm{q}_{5 \%(50 ; 150)} \times 13,09}{\sqrt{4}}=\frac{5,7710567 \times 13,09}{\sqrt{4}}=37,78 \%$.

Então, pode-se inferir que, para avaliar massa verde de feijão de porco, no delineamento blocos ao acaso, com até 50 tratamentos, quatro repetições são suficientes para identificar, como significativas a $5 \%$ de probabilidade, pelo teste de Tukey, diferenças entre médias de tratamentos de $55,48 \%, 39,66 \%$ e $37,78 \%$ das médias de massa verde de vagens, de massa verde de parte aérea sem vagens e de massa verde de parte aérea do experimento, respectivamente.

\section{CONCLUSÃO}

Os tamanhos ótimos de parcela para avaliar a massa verde de vagens, a massa verde de parte aérea sem vagens e a massa verde de parte aérea de feijão de porco (Canavalia ensiformis) são, respectivamente, $8,59 \mathrm{~m}^{2}, 6,14 \mathrm{~m}^{2}$ e $5,85 \mathrm{~m}^{2}$. Quatro repetições, para avaliar até 50 tratamentos, no delineamento blocos ao acaso, são suficientes para identificar, como significativas a $5 \%$ de probabilidade, pelo teste de Tukey, diferenças entre médias de tratamentos de $55,48 \%, 39,66 \%$ e $37,78 \%$ das médias de massa verde de vagens, de massa verde de parte aérea sem vagens e de massa verde de parte aérea do experimento, respectivamente.

\section{AGRADECIMENTOS}

Ao Conselho Nacional de Desenvolvimento Científico e Tecnológico (CNPq) e à Coordenação de Aperfeiçoamento de Pessoal de Nível Superior (CAPES), pela concessão de bolsas aos autores. À Fundação de Amparo à Pesquisa do Estado do Rio Grande do Sul (FAPERGS) pela bolsa de iniciação científica e auxílio financeiro. Aos alunos bolsistas e voluntários pelo auxílio na coleta de dados.

\section{REFERÊNCIAS}

ALMEIDA, K.; CAMARA, F.L.A. Produtividade de biomassa e acúmulo de nutrientes em adubos verdes de verão, em cultivos solteiros e consorciados. Revista Brasileira de Agroecologia, v.6, p.55-62, 2011. Disponível em: <http://orgprints.org/23073/1/ Almeida_Produtividade.pdf $>$. Acesso em: 26 fev. 2014.
CARDOSO, D.P. et al. Atributos fitotécnicos de plantas de cobertura para a proteção do solo. Revista Verde de Agroecologia e Desenvolvimento Sustentável, v.8, p.19-24, 2013. Disponível em: <http://www.gvaa.com.br/revista/index.php/RVADS/article/ viewFile/1798/pdf_433>. Acesso em: 26 fev. 2014.

CARGNELUTTI FILHO, A. et al. Tamanhos de parcela e de ensaio de uniformidade em nabo forrageiro. Ciência Rural, v.41, p.1517-1525, 2011. Disponível em: <http://www.scielo.br/pdf/cr/ v41n9/a9911cr5182.pdf>. Acesso em: 26 fev. 2014. doi: 10.1590/ S0103-84782011005000119.

CARNEIRO, M.A.C. et al. Produção de fitomassa de diferentes espécies de cobertura e suas alterações na atividade microbiana de solo de cerrado. Bragantia, v.67, p.455-462, 2008. Disponível em: <http://www.scielo.br/pdf/brag/v67n2/a21v67n2.pdf>. Acesso em: 26 fev. 2014. doi: 10.1590/S0006-87052008000200021.

CARVALHO, W.P. et al. Desempenho agronômico de plantas de cobertura usadas na proteção do solo no período de pousio. Pesquisa Agropecuária Brasileira, v.48, p.157-166, 2013. Disponível em: <http://www.scielo.br/pdf/pab/v48n2/48n02a05.pdf >. Acesso em: 26 fev. 2014. doi: 10.1590/S0100-204X2013000200005.

CESAR, M.N.Z. et al. Performance de adubos verdes cultivados em duas épocas do ano no Cerrado do Mato Grosso do Sul. Revista Brasileira de Agroecologia, v.6, p.159-169, 2011. Disponível em: <http://orgprints.org/23081/1/Cesar_Perfomance.pdf>. Acesso em: 26 fev. 2014.

LOPES, O.M.N. Feijão-de-porco: leguminosa para adubação verde e cobertura de solo. Belém: Embrapa Amazônia Oriental, 1998. 4p. (Recomendações Básicas, 37). Disponível em: <http://www.infoteca.cnptia.embrapa.br/bitstream/doc/375234/1/ RecBas37.pdf>. Acesso em: 26 fev. 2014.

MAIA, F.E.N. et al. Biomassa de feijão de porco sob diferentes densidades de semeadura em Mossoró, RN. Agropecuária Científica no Semiárido, v.9, p.43-49, 2013. Disponível em: <http://150.165.111.246/ojs-patos/index.php/ACSA/article/ viewFile/272/pdf>. Acesso em: 26 fev. 2014.

PARANAÍBA, P.F. et al. Tamanho ótimo de parcelas experimentais: proposição de métodos de estimação. Revista Brasileira de Biometria, v.27, p.255-268, 2009. Disponível em: <http://jaguar. fcav.unesp.br/RME/fasciculos/v27/v27_n2/Patricia.pdf>. Acesso em: 31 out. 2013.

PIMENTEL-GOMES, F. Curso de estatística experimental. 13.ed. Piracicaba: Nobel, 1990. 468p.

R DEVELOPMENT CORE TEAM. R: a language and environment for statistical computing. Vienna, 2014. Disponível em: 〈http://www.R-project.org>. Acesso em: 26 fev. 2014.

TEIXEIRA, C.M. et al. Liberação de macronutrientes das palhadas de milheto solteiro e consorciado com feijão-de-porco sob cultivo de feijão. Revista Brasileira de Ciência do Solo, v.34, p.497506, 2010. Disponível em: <http://www.scielo.br/pdf/rbcs/v34n2/ v34n2a23.pdf $>$. Acesso em: 26 fev. 2014. doi: 10.1590/S010006832010000200023.

TEIXEIRA, C.M. et al. Fitomassa, teor e acúmulo de micronutrientes do milheto, feijão-de-porco e guandu-anão, em cultivo solteiro e consorciado. Acta Scientiarum. Agronomy, v.30, p.533-538, 2008. Disponível em: <http://periodicos.uem.br/ ojs/index.php/ActaSciAgron/article/view/5314>. Acesso em: 26 fev. 2014. doi: 10.4025/actasciagron.v30i4.5314. 